\title{
Error predictions for average end diameter sectional formula in tree stem volume measurement
}

\author{
Predicciones de error para la fórmula seccional del promedio de diámetros extremos \\ en la medición del volumen de tronco de árbol
}

\begin{abstract}
Gildardo Cruz de León ${ }^{a *}$, Isaac Alfaro-Trujillo a, Margarita Bañuelos-Jiménez a
*Corresponding author: a Universidad Michoacana de San Nicolás de Hidalgo, Facultad de Ingeniería en Tecnología de la Madera, Apartado Postal 580, C.P. 58000, Morelia Michoacán, México, tel./fax: (443) 32603 79, gcruzl@umich.mx
\end{abstract}

SUMMARY

The use of the sectional formula given by the product of the cross sectional area related to the average of segment end diameters, times segment length, is a known method to estimate the volume of a tree stem segment. The whole tree stem volume can be obtained summing volumes of individual segments. There is not a formal study about the errors in using that method that allows comparing it to other conventional methods. In this work, following a theoretical procedure proposed recently in the forest measurement literature, those errors were computed. The method was evaluated applying it to the geometries of paraboloid, cone, and neiloid, to get the errors in tree stem volume estimation as function of a given number of segments, $n$. The average absolute percent errors were: $\leq 10.9 \%$ for $n \geq 5$; $\leq 5.5 \%$ for $n \geq 10 ; \leq 2.8 \%$ for $n \geq 20 ; \leq 1.9 \%$ for $n \geq 30$. Compared to known results, the method is better than Smalian and Huber methods, though it is not for the frustum of cone volume formula. Additionally, there are algebraic proves showing that the segment volume estimated by the method is lower than the volume for frustums of paraboloid and cone; in this work, the proof that it is also lower than the volume for a frustum of neiloid is provided, which completes the corresponding knowledge on the subject.

Key words: sectional methods, subneiloid, applied mathematics.

\section{RESUMEN}

El uso de la fórmula seccional dada por el producto del área transversal asociada al promedio de diámetros extremos de segmento por la longitud del segmento, es un método conocido para estimar el volumen de un segmento de fuste de árbol. El volumen completo del fuste puede obtenerse sumando volúmenes de segmentos individuales. No hay un estudio formal acerca de los errores en el uso de ese método que permita compararlo con otros métodos convencionales. En este trabajo, utilizando un procedimiento teórico propuesto recientemente en la literatura de mediciones forestales, se calcularon dichos errores. El método fue evaluado aplicándolo a las geometrías de paraboloide, cono y neiloide, para obtener los errores en la estimación del volumen de un fuste de árbol como función de un número dado de segmentos, $n$. Los errores porcentuales absolutos promedio fueron: $\leq 10,9 \%$ para $n \geq 5 ; \leq 5,5 \%$ para $n \geq 10 ; \leq 2,8 \%$ para $n \geq$ $20 ; \leq 1,9 \%$ para $n \geq 30$. Comparando con resultados conocidos, el método es más preciso que los métodos de Smalian y Huber pero no lo es para la fórmula de volumen de cono truncado. Adicionalmente, existen pruebas algebraicas de que el volumen de segmento estimado por este método es menor que el volumen de los truncados de paraboloide y cono; en este trabajo, se aporta la prueba que muestra que es también menor que el volumen de un truncado de neiloide, lo cual completa el conocimiento correspondiente sobre el tema.

Palabras clave: métodos seccionales, subneiloide, matemáticas aplicadas.

\section{INTRODUCTION}

Progressively, more complex and accurate methods for tree stem volume estimates are being proposed as part of the knowledge evolution in forest measurements. However, the simplest old sectional methods are still preferred for practical measurements. According to Briggs (1994), among the most known sectional methods are: the Newton, Smalian, Huber, Bruce, Frustum of cone, and the cross sectional area related to the average of segment end diameters, times the segment length, method. The New- ton method is not practical while the Bruce's method was developed for butt logs (Bruce 1982). The four remaining methods are possibly the most conventional worldwide. Errors in the use of Smalian and Huber methods as function of the number of segments have been calculated by Cruz de León and Uranga-Valencia (2013) and for the frustum of cone method by Cruz de León et al. ${ }^{1}$ The present work is aimed at determining errors in the remaining method out of the four revised methods.

Cruz de León G, LP Uranga-Valencia, M Bañuelos Jiménez. 2014. Unpublished. 
The referred method is as old and easy to use as the Huber, Smalian, and the truncated of cone methods. However, it has not been given a conventional name; Graves (1906) refers to it as the average end diameter method; Grosenbaugh (1954) and Briggs (1994) call it the subneiloid method; Fonweban (1997) name it the Avend method. In agreement with Graves (1906), in this work it will be named the average end diameter method and it will be denoted as AED.

Graves (1906) and Fonweban (1997) point the use of AED in some regions of Europe. In a manual for Australian farmers, Reid and Stephen (2001) suggested the use of the Huber, Smalian and AED methods. Particularly, in the state of Michoacán, México, AED has been officially used to train forest farmers for log volume estimation (Medrano-Farfán 1999).

The main problem for this work can be stated by the question: is AED as reliable as the other three conventional methods for whole tree stem volume estimation by sections? It is conjectured here that: if the errors in the use of AED can be determined, and result in the error range of those methods, then AED is a reliable method.

Graves (1906) algebraically proves that the volume predicted by AED is lower than those for the frustums of paraboloid and cone with the same end diameters. Grosenbaugh (1954) numerically shows that AED formula gives lower volumes, though close to a truncated of neiloid; he defines a hypothetical solid of revolution, named subneilod, for which the AED formula gives the exact frustum volume. The corresponding general algebraic proof is unknown. That complementary problem is also addressed in this work.

Standard forest measurement literature agrees that the geometry of most tree stem segments lies around a cone and between paraboloid and neiloid (Cruz de León and Uranga-Valencia 2013). The main objective in this work is to calculate the errors for the AED method applied to tree stems modeled through the former three geometries as function of the number of segments. The specific objectives are: i) to compare the errors of the AED method to those obtained for the other three methods; ii) to obtain the general algebraic proof that the AED volume is lower than the truncated of neiloid's volume.

\section{METHODS}

Cruz de León and Uranga-Valencia (2013) proposed a methodology to calculate errors in volume estimation for the application of any sectional method to tree stems, as a function of the number of segments. That procedure was used to evaluate the AED method and test the conjecture of this work. It is based on approximation methods of calculus to get the volume for solids of revolution, the classical theory of tree stem form and volume, and an error analysis from forest measurement by means of the average percent error (APE) and the average absolute per- cent error (AAPE). Although those parameters of error are commonly used for random errors in forest measurements, the kind of errors regarded in the referred methodology are of systematic nature, due only to the finite number of segments involved in the solid of revolution's volume estimation. Then, the mathematical analysis is mainly based on calculus and not on statistics. The known property that a sectional method either over-estimates or under-estimates volume for a given geometry is characterized by those systematic errors.

The classical geometries. In the forest measurement traditional literature, stem shape is modeled through a generating function $y(x)$ defined by the equation,

$$
y^{2}=A_{m} x^{m}
$$

where $x$ and $y$ represent stem height from the tip and radius respectively, $A_{m}$ is a constant and $m=0,1,2$, and 3, for the corresponding solids of revolution, cylinder, paraboloid, cone, and neilod, respectively. They are called the classical geometries in agreement with Dieguez-Aranda et al. (2003).

Sectional method. It is any method to estimate volume for a tree stem segment or log taking it as a cylinder of defined average cross sectional area and length equal to the segment length (Avery and Burkhart 2002). A particular average cross sectional area defines the corresponding method as it is shown below for the AED method.

The average end diameter method (AED). For a tree stem segment or log of length $L$, smaller end diameter $d$, and bigger end diameter $D$, the AED method for its volume estimation is defined by

$$
V_{A E D}=\left\lfloor\frac{\pi}{4}\left(\frac{D+d}{2}\right)^{2}\right\rfloor L=\left[\frac{\pi}{4}\left(\frac{D^{2}+2 D d+d^{2}}{4}\right)\right] L
$$

The term inside square brackets of equation [2] defines the average cross sectional area for the AED method.

General notation for the volumes. The individual volumes of tree stem segments for the AED method are called $V_{A E D, m, n, i}$, where $m=1,2,3$ refers to the geometry, $n$ to the number of segments, and $i$ is the number of a specific segment. The total volume, given by the sum of the individual ones, is denoted as $V_{A E D, m, n}$. Their corresponding normalized volumes are $v_{A E D, m, n, i}$, and $v_{A E D, m, n}$.

\section{RESULTS}

Derivation of the individual volume of segment for the AED method. For a classical geometry of length $H$ sectioned in $n$ segments, of length $(H / n)$, the $x_{i}$ coordinates for the divisions of those intervals are $(i H / n)$, where $i=1,2, \ldots, n$. 
In agreement to equation [1], their square radiuses are given by

$$
y_{i}^{2}=A_{m} x_{i}^{m}=A_{m}(i H / n)^{m}
$$

Taking $d=2 y_{i-1}$ and $D=2 y_{i}$ in equation [2], results

$$
V_{A E D, m, n, i}=\pi\left(\frac{y_{i}^{2}+2 y_{i} y_{i-1}+y_{i-1}^{2}}{4}\right) L
$$

Using equation [1] to get $y_{i-1}$ and $y_{i}$, as function of $x_{i-1}=(i-1)$ $H / n$, and $x_{i}=i H / n$, respectively, taking $L=\left(x_{i}-x_{i-1}\right)=(H / n)$, and substituting them in equation [4], results

$$
V_{A E D, m, n, i}=\frac{\pi A_{m} H^{m+1}}{4 n}\left[\left(\frac{i}{n}\right)^{m}+2 \sqrt{\left(\frac{i}{n}\right)^{m}\left(\frac{i-1}{n}\right)^{m}}+\left(\frac{i-1}{n}\right)^{m}\right]
$$

The normalized volume of segment for AED is given by $v_{A E D, m, n, i}=V_{A E D, m, n, l} / \pi A_{m} H^{m+1}$; then,

$$
v_{A E D, m, n, i}=\frac{1}{4 n^{m+1}}\left[i^{m}+2 \sqrt{i^{m}(i-1)^{m}}+(i-1)^{m}\right]
$$

It was obtained for each geometry $m=1,2$, and 3 , as function of $i$, and for $n=5,10,20$, and 30. All the individual normalized volumes of segments were computed to get the total normalized volumes and the APE and AAPE values shown below.

Total normalized volumes and average percent errors as function of the number of segments. The total normalized volumes and average percent errors obtained by the AED method for the different geometries as function of the number of segments as well as the exact values are shown in table 1 .

Average absolute percent errors. The differences in total normalized volumes related to the exact values are signifi- cant only for the cases $n=5,10,20$ and 30 . Table 1 shows the APE values corresponding to those $n$ values, for the AED method, and the studied geometries. Specifically for this work, it was enough to calculate APE because AAPE $=|\mathrm{APE}|$.

\section{DISCUSSION}

The results given in table 1 confirm that the AED volumes are lower than the volumes for frustums of paraboloid and cone, in agreement with Graves (1906), and lower than the volume for frustum of neiloid, in agreement with Grosenbaugh (1954).

Maximum AAPE can be taken as error upper-limits. As table 1 shows, the AAPE in using the AED method to estimate tree stem volumes are: $(\leq 10.9 \%$ for $n \geq 5 ; \leq 5.5 \%$ for $n \geq 10 ; \leq 2.8 \%$ for $n \geq 20 ; \leq 1.9 \%$ for $n \geq 30$ ). The maximum AAPE for AED is between $1.9 \%$ and $10.9 \%$.

The maximum AAPE for Smalian goes from $5 \%$ to $27 \%$ and for Huber from $2.5 \%$ to $13.5 \%$ (Cruz de León and Uranga-Valencia 2013). Hence, AED is better than Smalian and Huber methods. However, AED is not better than the method which uses the frustum of cone formula whose maximum AAPE is between $1.5 \%$ and $8.4 \%^{2}$.

That the AED method should be better than Smalian is in agreement with Briggs (1994) and Fonweban (1997) for the case of individual logs but it is not for the Huber method (Fonweban 1997). For a whole tree stem, more experimental studies are required to determine whether AED is better than the Huber method, as theory predicts. They should be sufficiently accurate because both methods differ by less than $3 \%$.

Table 1 shows that AED and neiloid volumes are very close with errors under $1 \%$ for $n \geq 5$. As an original contribution, in the appendix, it is provided the general proof that the predicted volume by AED is lower than the corresponding volume obtained by the frustum of neiloid formula. Similar proves for frustums of paraboloid and cone have been reported by Graves (1906).

\footnotetext{
See footnote 1.
}

Table 1. Total normalized volumes and average percent errors, APE, of paraboloid, cone, and neiloid, for the average end diameter method, AED, as function of the number of segments, $n$.

Volúmenes totales normalizados y errores porcentuales promedio, APE, de paraboloide, cono y neiloide, para el método del promedio de diámetros extremos, AED, como función del número de segmentos, $n$.

\begin{tabular}{cccccccccc}
\hline & \multicolumn{3}{c}{ Paraboloid } & \multicolumn{3}{c}{ Cone } & \multicolumn{3}{c}{ Neiloid } \\
\cline { 2 - 10 } & $v_{E x a c t, 1, n}$ & $v_{A E D, 1, n}$ & APE & $v_{E x a c t, 2, n}$ & $v_{A E D, 2, n}$ & APE & $v_{E x a c t, 3, n}$ & $v_{A E D, 3, n}$ & APE \\
\hline 5 & 0.5 & 0.485999 & -10.9 & 0.333333 & 0.330000 & -6.2 & 0.25 & 0.248830 & -0.8 \\
10 & 0.5 & 0.496067 & -5.5 & 0.333333 & 0.332500 & -3.2 & 0.25 & 0.249693 & -0.5 \\
20 & 0.5 & 0.498908 & -2.8 & 0.333333 & 0.333125 & -1.6 & 0.25 & 0.249922 & -0.3 \\
30 & 0.5 & 0.499487 & -1.9 & 0.333333 & 0.333241 & -1.1 & 0.25 & 0.249966 & -0.2 \\
\hline
\end{tabular}


The total normalized volume of Cruz de León and Uranga-Valencia (2013) corresponds exactly to the absolute form factor for a given method and geometry. Hence, table 1 gives approximations to the absolute form factors for paraboloid (1/2), cone (1/3), and neiloid (1/4), as a function of the number of segments, related to the AED method. That means to model those geometries as a sequence of frustums of subneiloids and a subneiloid at the tip. Table 1 simultaneously gives the corresponding errors in volume and form estimation.

The Smalian method is more practical than the Huber method and, frequently, it is preferred even when it involves a much higher error than those in the latter (Husch et al. 1982). AED and Smalian are at the same practical level because both methods need the same measurements as input: end diameters, and length of segment. The results of this work show that AED involves errors lower in magnitude but closer to the Huber method.

\section{CONCLUSIONS}

It is possible to evaluate theoretically the AED method using the suggested methodology. The error limits in using the AED method for whole tree stem volume estimation by sections were obtained. Particularly, results predict that the AED method should be better than the Huber and Smalian methods though not better than the method which uses the frustum of cone formula. That proves the conjecture of this work. It was proved here that the predicted volume by AED is lower than the corresponding volume given by the frustum of neiloid formula, which completes that kind of proves for the three main geometries used in the approach for tree stem form.

AED contains both, practicality and accuracy, of the Smalian and Huber methods, respectively. The former features are enough to justify and support the use of the AED method; it can be regarded as a reliable method for whole tree stem volume measurements.

\section{ACKNOWLEDGMENT}

This work was supported by Coordinación de la Investigación Científica de la Universidad Michoacana de San Nicolás de Hidalgo, Morelia Michoacán, México.

\section{REFERENCES}

Avery TE, HE Burkhart. 2002. Forest Measurements. New York, USA. Mc Graw Hill. 456 p.

Briggs DG. 1994. Forest Products Measurements and Conversion Factors. Seattle, USA. College of Forest Resources, University of Washingthon. $161 \mathrm{p}$.

Bruce D. 1982. Butt Log Volume Estimators. Forest Science 28(3):489-503.

Cruz de León G, LP Uranga-Valencia. 2013. Theoretical evaluation of Huber and Smalian methods applied to tree stem classical geometries. Bosque 34(3):311-317.

Diéguez-Aranda U, M Barrio-Anta, F Castedo-Dorado, AD Ruíz-González, MF Álvarez-Taboada, JG Álvarez-González, A Rojo-Albareca. 2003. Dendrometría. Madrid, España. Mundi-Prensa. 327 p.

Fonweban JN. 1997. Effect of log formula, log length and method of measurement on the accuracy of volume estimates for three tropical timber species in Cameroon. Commonwealth Forestry Review 76(2):114-120.

Graves HS. 1906. Forest Mensuration. New York, USA. John Wiley. $458 \mathrm{p}$.

Grosenbaugh LR. 1954. New tree-measurement concepts: height accumulation, giant tree, taper and shape. Occasional paper 134. New Orleans, USA. Southern Forest Experiment Station, USDA (United States Department of Agriculture) Forest Service. $25 \mathrm{p}$.

Husch B, ChI Miller, TW Beers. 1982. Forest mensuration. New York, USA. John Wiley. 402 p.

Medrano-Farfán H. 1999. Cubicación de Madera. Morelia, Michoacán, México. Comisión Forestal del Estado de Michoacán. $15 \mathrm{p}$.

Reid R, P Stephen. 2001. The Farmers Forest: multipurpose forestry for Australian farmers. Melbourne Australia. RIRDC (Rural Industries Research and Development Corporation). 167 p.

Recibido: 14.10 .15

Aceptado: 28.12.15 


\section{APPENDIX}

Proof on that the sectional volume for the AED method is lower than the corresponding one for frustum of neiloid. The volume for a frustum of neiloid of length $L$, and smaller and bigger end cross sectional areas $s$ and $S$, respectively, is given by

$$
V_{\text {Neiloid }}=\frac{1}{4}\left(s+\sqrt[3]{s^{2} S}+\sqrt[3]{s S^{2}}+S\right) L .
$$

The volume predicted by AED for a segment of the same former conditions can be obtained from equation [10], taking $s=(\pi / 4) d^{2}$ and $S=(\pi / 4) D^{2}$ as

$$
V_{A E D}=\frac{1}{4}(s+2 \sqrt{s S}+S) L .
$$

Making some algebra it happens that

$$
V_{\text {Neiloid }}-V_{A E D}=\frac{1}{4}\left(\sqrt[3]{s^{2} S}+\sqrt[3]{s S^{2}}-2 \sqrt{s S}\right) L
$$

$$
\begin{aligned}
& =\frac{1}{4}\left(s^{4 / 6} S^{2 / 6}+s^{2 / 6} S^{4 / 6}-2 s^{3 / 6} S^{3 / 6}\right) L \\
& =\frac{1}{4} S^{2 / 6} S^{2 / 6}\left(s^{2 / 6}+S^{2 / 6}-2 s^{1 / 6} S^{1 / 6}\right) L \\
& =\frac{1}{4} S^{1 / 3} S^{1 / 3}\left(s^{1 / 6}-S^{1 / 6}\right)^{2} L .
\end{aligned}
$$

By definition, $s>0, S>0$, and $L>0$, then, $\left(s^{1 / 3} S^{1 / 3} L\right)>0$. Also, as the square of any number different of zero is positive, $\left(s^{1 / 6}-S^{1 / 6}\right)^{2}>0$, it results that $\left(V_{\text {Neiloid }}-V_{A E D}\right)>0$, what means that $V_{\text {Neiloid }}>V_{A E D}$. Then, it has been proved that the volume of AED is lower than the volume for the frustum of neiloid, what explains the corresponding results of table 1 , and the name of subneiloid given to the AED method by Grosenbaugh (1954). 
